Submission \# 11136

\title{
Organizational Citizenship Behavior in the People's Republic of China
}

\author{
Jiing-Lih Farh \\ Department of Management of Organizations \\ Hong Kong University of Science and Technology \\ Clear Water Bay, Kowloon \\ Hong Kong \\ (852) 2358-7735 \\ mnlfarh@ust.hk \\ Chen-Bo Zhong \\ Department of Management of Organizations \\ Hong Kong University of Science and Technology \\ Clear Water Bay, Kowloon \\ Hong Kong \\ (852) 2358-7735 \\ jameszh@ust.hk \\ Dennis W. Organ \\ School of Business \\ Indiana University \\ Bloomington. Indiana \\ organ@indiana.edu
}

Correspondence to:

Jiing-Lih Farh

Department of Management of Organizations

Hong Kong University of Science and Technology

Clear Water Bay, Kowloon

Hong Kong

(852) 2358-7735

mnlfarh@ust.hk

Paper presented at annual meeting of Academy of Management and published in Best Paper Proceedings 


\title{
Organizational Citizenship Behavior in the People's Republic of China
}

\begin{abstract}
Western scholars have increasingly emphasized the importance of employee actions that are not specifically designated in their formal job duties, or organizational citizenship behavior (OCB). Most of these studies were conducted in the U.S. using US employee population as samples. Using an inductive approach, we examined forms of OCB in the People's Republic of China, a socialist country with strong collectivism. From a diverse sample of 166 employees and managers in 75 state-owned, collective, joint venture, and private enterprises in the PRC, we collected 756 OCB items that were commonly observed at workplace. These items were then subjected to a rigorous content analysis to identify major forms of OCB. Results of our analysis revealed 11 dimensions of OCB with six dimensions not evident in the Western literature. Types of organizations influenced the reporting of various forms of OCB. Results suggested that Chinese formulation of OCB differs from its Western counterparts, and is embedded in its unique social and cultural context.
\end{abstract}

Key words: Organizational Citizenship Behavior, National Culture, China 


\section{Introduction}

Nearly four decades ago, Katz (1964) pointed out the importance of a class of innovative and spontaneous behaviors, which are beyond role requirements but essential for accomplishment of organizational functions. Following the pioneer research by Dennis Organ and his associates (Smith, Organ \& Near, 1983), this class of behavior was later conceptualized as organizational citizenship behavior (OCB), broadly defined as "individual behavior that is discretionary, not directly or explicitly recognized by the formal reward system, and that in the aggregate promotes the effective functioning of the organization" (Organ, 1988: 4). In subsequent research, several related concepts of OCB have been proposed and examined, including extrarole behavior (Van Dyne, Cummings, \& McLean Parks, 1995; Van Dyne, \& LePine, 1998), civic citizenship (Graham, 1991; Van Dyne, Graham, \& Dienesch, 1994), prosocial behavior (Brief \& Motowidlo, 1986), organizational spontaneity (George \& Brief, 1992), and contextual performance (Borman \& Motowidlo, 1993; Motowidlo, Borman \& Schmit, 1997).

Despite a considerable amount of empirical research on conceptualizing and categorizing $\mathrm{OCB}$, the proliferation of related constructs and dimensions of OCB in recent years indicates that the academic community has not been able to settle on a single, well-defined construct for OCB. Organ, for example, proposed that it is no longer fruitful to regard OCB as "extra-role", "beyond the job", or "unrewarded by the formal system" due to the fuzziness of the concepts of "role" and "job" and "guaranteed contractual reward", and thus favored to conceptualize OCB in terms of contextual performance (Organ, 1997). Van Dyne et al., on the other hand, insist that 
classifying a specific behavior as in-role or extra-role is theoretically significant, although it is empirically difficult due to the dynamic and relative nature of extra-role behavior (Van Dyne, Cummings, \& McLean Parks, 1995).

Recent research also shows that there is no clear, common understanding about OCB across organizational participants (Lam, Hui, \& Law, 1999; Morrison, 1994). Morrison (1994) found that employees holding the same formal job differed in how broadly they defined their jobs. She also found that not only employees holding the same job with different levels of job satisfaction, commitment and tenure tended to define in-role and extra-role differently, but also employees and their supervisors differed in how broadly they defined in-role behavior. With much uncertainty about the construct, it is not surprising that Organ reported that "no definitive measure of OCB exists, and empirical analyses of existing measures have not shown entirely consistent results, so the articulation of different forms of OCB must necessarily go somewhat beyond the available data" (Organ, 1988: 8).

Even less is known about OCB in a global context. With the exception of Farh, Earley, and Lin (1997), the current concept of OCB and its related measures were all developed by Western researchers using Western samples in a Western social cultural context. We do not know if the current dimensions of OCB as identified in the Western literature are culture invariant. Using an inductive approach, we sought to understand the content domain or dimensions of OCB in the People's Republic of China, a socialist country with strong collectivism. We compared the dimensions identified in the PRC with those in the Western literature. We also examined the potential impact of the positions of the respondent and the type of the organizations in 
which the respondent was employed on the content domain of OCB in the PRC. This research helps us not only understand the dimensions of OCB in the PRC context, but also determine which OCB dimensions in the current literature are more etic (universal) or emic (culture specific).

\section{Major Dimensions of OCB in the Western Literature}

In this section we identified major dimensions of OCB in the Western literature. We limit our review to the Western literature exclusively because we wish to contrast $\mathrm{OCB}$ in the West versus $\mathrm{OCB}$ in the PRC. We further limit our review to dimensions of OCB that have been operationalized and investigated in the Western literature. In other words, we excluded those dimensions that were discussed conceptually but not measured empirically. For example, Katz and Kahn (1978: 403) provided five examples of innovative and spontaneous behaviors: a) cooperative activities with fellow members, b) actions protective of system or subsystem, c) creative suggestions for organizational improvement, d) self-training for additional organizational responsibility, and e) creation of favorable climate for organization in the external environment. Among these five classes of behavior, category (b) and (d) have not been followed up in subsequent empirical research. We do not include them as major dimensions of OCB in the Western literature.

Empirical dimensions for OCB was first identified and measured by Smith, Organ and Near (1983). In deriving their dimensions and measures, Smith et al. (1983) conducted semi-structured interviews with a number of managers from several organizations. They asked these managers to identify instances of helpful, but not 
absolutely required, job behaviors. A pool of such items was then pilot tested with a sample of managers, and ensuing factor analysis distilled them into two dimensions: altruism and generalized compliance. These are the primary dimensions of OCB, which have been used broadly in subsequent research.

Five years later, Organ reviewed the empirical literature on OCB and found that no definitive measure of OCB existed (Organ, 1988). He synthesized the literature and identified three more dimensions of OCB: sportsmanship, courtesy, and civic virtue. Adding altruism and conscientiousness (which was renamed from generalized compliance) to the three, Organ proposed a five-dimension system of OCB. Subsequently Podsakoff, MacKenzie, Moorman, \& Fetter (1990) developed empirical measures for each of the five dimensions of OCB. Organ's classification along with Podsakoff et al.'s measure became the most popular formulation of OCB in the literature.

Drawing from research in political science, Graham (1991) proposed an alternative conceptualization of $\mathrm{OCB}$, called civic citizenship. Civic citizenship was defined as a global concept that includes all positive organizationally relevant behaviors of individual organization members. Graham identified three major forms of civic citizenship: a) organizational obedience, b) organizational loyalty, and c) organizational participation. This conceptualization of OCB was validated and organizational participation was further broken down into social participation, advocacy participation and functional participation by Van Dyne, Graham and Dienesch (1994). As expected, there is a considerable amount of overlap in content domain between civic citizenship and Organ's 5-dimensional OCB. Three 
dimensions of Graham's civic citizenship --functional participation, advocacy participation, and loyalty are, however, relatively distinct from Organ's classification and have been investigated in empirical study.

Van Dyne, Cummings and McLean Parks (1995) proposed a typology to synthesize various forms of extra-role behavior. Their typology is divided along two dimensions: promotive versus prohibitive, and affiliative versus challenging. Promotive behaviors are proactive which promote, encourage, or cause things to happen. Prohibitive behaviors are protective and preventative, including interceding to protect those with less power as well as speaking out to stop inappropriate or unethical behavior. Affiliative behavior is interpersonal and cooperative, which strengthens relationships and is other-oriented. Challenging behavior emphasizes ideas and issues, which is change-oriented and can damage relationships. Based on the two dimensions, four types of extra-role behavior were identified: voice, helping, stewardship, and whistle-blowing. In a subsequent study, Van Dyne and LePine (1998) validated two types of extra-role behavior: voice and helping. Helping was similar to altruism. Voice, which is defined as promotive behavior that emphasizes expression of constructive challenge intended to improve rather than merely criticize, may be considered another distinct dimension of OCB. 
Based on the above review, we identified nine major dimensions of OCB in the Western literature. They are altruism, conscientiousness, loyalty, civic virtue, voice, functional participation, sportsmanship, courtesy, and advocacy participation. These dimensions along with their definitions and sources are summarized in Table 1.

\section{National Culture and OCB}

It has been long noted that human perceptions are subjective and socially constructed, and thus subject to the influence of a variety of social cues (Graen, 1976; Salancik \& Pfeffer, 1978). A recent study by Morrison (1994) has shown that employee's perception of job breadth was positively related to satisfaction and to affective and normative commitment and negatively related to tenure. Moreover, she found that employees and supervisors differed markedly in how they defined employees' job breadth. If job definitions differ within in a single organization in a single culture, how much more differences in the formulation of OCB can we expect when we cross cultural boundaries? However, empirical studies of OCB in nonwestern cultures are rare. Farh, Earley and Lin (1997) derived OCB dimensions empirically in a non-western cultural context. These researchers asked a sample of employees from Taiwan to generate a large number of OCB incidents. These incidents were sorted and then classified into categories, investigated with an independent sample to derive dimensions. Five dimensions of OCB were found in Taiwan. Three of the five were similar to altruism, conscientiousness, and civic virtues as described by Organ (1988), suggesting that these Western derived OCB dimensions transcend cultural boundaries. The other two dimensions, protecting 
company resources and interpersonal harmony, have not been examined in the Western literature, suggesting that they are dimensions unique to Taiwan. The Farh et al. (1997) study suggests that some OCB dimensions are etic (universal) in nature and others emic (specific to a cultural context).

Using the OCB items in the scale developed by Podsakoff et al. (1990), Lam, Hui and Law (1999) investigated the perceived job role boundary of the subordinates in four countries (the U.S., Australia, Japan, and Hong Kong). This study found that employees from Hong Kong and Japan were more likely to rate courtesy and sportsmanship as part of their job roles than employees from the U.S. and Australia. Furthermore, employees from the four countries did not differ on altruism, conscientiousness, and civic virtue in terms of perceived job role boundary. This study corroborates the finding by Farh et al. (1997) and suggests that some dimensions of OCB may transcend cultural boundaries and others may not. The current study contributes to the literature on understanding which OCB dimensions can transcend cultures and which can not by examining OCB in the PRC context.

\section{OCB in the PRC Context}

We identified three prominent cultural or institutional characteristics of the PRC that may have some direct bearing on the construct domain of OCB by Chinese employees.

The Salience of Interpersonal Relationship 
It has been observed by cultural anthropologists that Chinese perceive human being as inseparable from his or her surrounding network (Hsu, 1971). For example, the Chinese character for man (ren) carries the meaning of connectedness and reciprocal relations, whereas the English word 'man' carries the meanings of separateness, free will, and individualism (Hsu, 1971). Moreover, Chinese was described as dominated by "social orientation" (Yang, 1993), which means that Chinese primarily attempt to establish and maintain a harmonious relationship with his or her social surroundings in daily life. The importance of personal relationship (called guanxi) in business dealings has also been well documented in the literature (Farh, Tsui, Xin, \& Cheng, 1998; Tsui \& Farh, 1997; Xin \& Pearce, 1996). The importance of interpersonal relationship in Chinese daily life suggests that some domains of Chinese OCB are likely to be related to social relations at workplace. For example, Yang (1993) identified four types of Chinese social orientation: familistic orientation, relationship orientation, authoritarian orientation and other orientation. Familistic orientation, which stresses the importance of family in Chinese daily life, and relationship orientation, which emphasizes the interpersonal relationship in Chinese daily life, were identified as accounting for the emergence of interpersonal harmony and protecting company resources as OCB dimensions unique in Taiwan in the study of Farh, Earley, and Lin (1997). We expect similar dimensions in our PRC sample.

\section{State Domination}

Before the economic reform that began in 1979, China was gripped by a system of central planning in which the government exercised a tight control over its 
enterprises and employees. This is one of the most significant features that distinguish organizations in the PRC before 1980's from its counterparts in the West. For example, before 1979, there was tight control by the Ministry of Labor over labor allocation. Workers and staff were assigned to organizations by the government without any say in the allocation process but accepting whatever jobs were given (Walder, 1983; Nyaw, 1995). Moreover, workers could not quit from the organization they were assigned to, otherwise it was impossible for them to get comparable positions in other organizations (Walder, 1983). The central allocation determined not only workers' jobs and careers, but also covered almost every aspect of their life.

In recent years, the state has loosened its control over its enterprises and employees in many areas of life. Even so, the state remains a most dominant force in the PRC. It wields enormous power over many aspects of business operations (e.g., state approval of investment projects, business loans, and licenses). We expect that OCB in the PRC context may reflect the domination of the state. For instance, employee participation in activities promoted by the state may be considered as OCB because it can help satisfy the demand that the state placed on its enterprises. The influence of the state is particularly strong for state-owned enterprises due to their higher dependence on the state for resources and key decisions.

\section{Broad Definition of Performance}

In the PRC the concept of performance (called biaoxian) takes on a completely different meaning than in the West. Biaoxian is an all encompassing concept. It refers to many aspects of life beyond the actual work the employees, 
including a) kinds of political opinions, suggestions, and criticisms voiced in meetings by employees, b) willingness to volunteer extra effort when asked, c) the character and integrity of the worker, d) willingness to accept orders without questioning them, e) ability to maintain cordial working relationship with co-workers and leaders, etc. (Walder, 1983). Many aspects of biaoxian are neither clearly defined in the worker's job responsibilities, nor can be contractually rewarded, but are generally expected by the social climate. Some elements of biaoxian seem to fall into the Western definition of OCB, while others go beyond any Western conception of OCB. Therefore, we expect that the content domain of OCB in the PRC will be broad and include dimensions that may not be ordinarily considered as OCB in the West.

\section{Contextual Influences on OCB: Position and Organization Type}

Previous research (Morrison, 1994) has shown that supervisors and subordinates differed in their perceptions of the breadth of the subordinate's job. Lam, Hui, and Law (1999) found that supervisors had broader definitions of job roles than subordinates. Based on these findings, we expect that respondent positions should influence the reporting of various forms of OCB in the PRC. We also expect that type of organizations in which the respondent is employed is likely to influence the reporting of various forms of $\mathrm{OCB}$ in the PRC. This is because employees in state-owned enterprises are more susceptible to the legacy of pre-reform communist policies than enterprises that are not under the direct control of the state such as joint ventures, private, and collective enterprises. 


\section{Method}

\section{Overview}

The purpose of this study was to identify the forms or classes of OCB in the PRC. Similar to the method used by Farh et al. (1997), we used an inductive approach to identify the dimensions (Hinkin, 1998). This approach called for gathering descriptions of behavioral incidents from respondents and then classified them into a number of categories by content analysis with an agreement index constructed using multiple judges (Anderson \& Gerbing, 1991; Kerlinger, 1986). This inductive approach is particularly important in cross-cultural research where construct and measurement equivalence can not be taken for granted (Van de Vijver, \& Leung, 1997).

We sampled a diverse group of PRC employees, presented them with a broad definition of OCB based on Organ (1988), and then asked them to list examples of OCB from their daily work environment. To avoid biasing their responses from prior categories of OCB developed in the West, we did not provide them with any OCB dimensions or examples. After building up a broad item pool, we proceeded with a rigorous item selection and classification process, which culminated in 11 OCB dimensions. We then compared these OCB dimensions with their Western counterparts.

\section{Sample Characteristics}


Since the PRC is an immensely diverse country and since we aimed to develop a broad understanding of OCB in the PRC context, we obtained a heterogeneous sample of participants. One hundred and sixty-six employees working in some 75 enterprises (including state-owned, collective, joint venture, and private companies) from four regions of China (Beijing, Shanghai, Shenzhen, and Tonglu—a small city in Eastern China) participated in our study. We recruited our sample through a variety of means: participants in university programs, personal interviews, etc. Table 2 summarized the characteristics of our sample.

\section{Definition of OCB}

In the study we presented respondents with the classical definition of organizational citizenship behavior as described by Organ (1988). OCB is defined as employee behavior that is spontaneous and discretionary in nature, not clearly listed as part of employee's job responsibilities, not directly rewarded by monetary rewards offered by the organization, and that, in the aggregate, makes for a more effective organization. The respondents were asked to list 5 to 10 of such behaviors based on their daily observation of the behavior of themselves or others in organizations.

\section{Item Pool}

The 166 respondents generated a total of 756 items (approximately 5 items per respondent). All items were transcribed onto 3" x 4" cards. The two Chinese authors of this paper plus a Chinese Ph.D. student screened all items based on two criteria: a) 
the item must have clear meaning in Chinese language; and b) the item must refer to employee behavior. A total of 66 items $(8.7 \%)$ was considered as "non-usable" (unclear meaning or not a behavior) and discarded from the item pool. This resulted in 690 usable items. The three-person screening panel then started to classify the 690 items into categories based on similarity of item content. After several iterations, they agreed upon a 27-category system, which could classify all 690 usable items into mutually exclusive categories. In other words, each item has a designated category. The number of items per category ranged from 2 to 66 .

\section{Reliability Test}

To test the reliability of our designated categories, we recruited 9 PRC Ph.D. students to serve as test judges. They worked in three separate panels, and each panel focused on one third of the 690 item pool. All judges went through a one-hour training session in which they were taught to be familiar with the definition of each category. They were then asked to classify 54 sample items ( 2 items per category) into the 27 category system as a training exercise. The whole training session took about an hour to complete.

Upon completion of the training, they classified one third of the usable items into the 27 categories. Since each item in the pool was classified by three test judges independently, there were four possible outcomes: a) full agreements--all three test judges classified the item into its designated category, b) two agreements--two of the three test judges classified the item into its designated category, c) one agreement-- 
only one of the three test judges classified the item into its designated category, and d) zero agreement--none of the three judges classified the item into its designated category. Table 2 presented the results of this reliability test. $73.8 \%$ (509 items) of the items were classified exactly the same way as the researchers, and 14.5\% (100 items) with one disagreement. 81 items $(11.8 \%)$ had two or three disagreements. Among those 81 items, six of them were retained after discussing with test judges. In total, we retained 615 items for subsequent analyses.

\section{Forming OCB Dimensions}

The 27-category system is not ideal in terms of scientific parsimony. We reduced 27 categories into 17 categories by first combining conceptually similar dimensions into broader, more abstract dimensions. Next, we eliminated categories that have few items. Our rationale here is that if a category had very few items, it implies that few employees observed such OCB behaviors in work settings. We applied a 2\% (13 items) cutoff rule. Six of the 17 categories were eliminated because they had fewer than 13 items in each category. This procedure resulted in $11 \mathrm{OCB}$ dimensions with 587 items.

\section{Results}

\section{Dimension of OCB}

Table 4 presents the 11 PRC OCB dimensions with their definitions and sample items and corresponding Western OCB dimensions, if available. These 11 
dimensions can be divided into two groups: 5 common dimensions and 6 extended dimensions. Common dimensions refer to PRC OCB dimensions whose content domains resemble those of the major OCB dimensions in the Western literature. Extended dimensions refer to OCB dimensions whose content domains differ from any of the existing Western OCB dimensions in the literature.

\section{Common Dimensions}

The first common dimension is called taking initiative, which refers to behaviors that indicate one's willingness to take on additional work responsibilities such as working overtime, extra duties, and cooperating with fellow workers. This dimension is quite similar to functional participation (Van Dyne, Graham, \& Dienesch, 1994) and job dedication (Van Scotter \& Motowidlo, 1996) in the Western

OCB literature. The dimension is the most frequently mentioned OCB dimension, accounting for 103 items (or $17.5 \%$ of the total).

The second common dimension is helping coworker, which refers to helping coworkers with organizationally relevant tasks or personal problems. This dimension is similar to altruism (Smith, Organ, \& Near, 1983) or helping (Van Dyne \& LePine, 1998) in the Western literature. However, helping coworker in the PRC seems to be broader in scope than altruism in the Western literature where altruism is typically limited to organizationally relevant tasks. In PRC, helping coworker includes coworker's personal problems as well. Helping co-worker included 12.2\% (72 items) of the OCB items. 
The third common dimension is Voice, which refers to raise constructive suggestions or speak up to prohibit harmful behavior to organization. Although we use the same name "voice" to label this dimension as Van Dyne and LePine (1998), our dimension of voice is somehow broader than voice dimension of Van Dyne and LePine (1998). It includes not only constructive challenges intended to improve but also prohibitive voice aimed at preventing others from doing harm to organization. Voice included 9.7\% (57 items) of the OCB items.

The fourth common dimension is participation in group activities, which refers to participation in activities organized by organization or by special groups of employees. This dimension is similar to civic virtue in the Western literature (Organ, 1988; Podsakoff, Mackenzie, Moorman \& Fetter, 1990) since both refer to participation in organizational life. However, civic virtue includes a broader scope of participation in organizational life such as keeping up with organization announcements, memos, and so on (Podsakoff et al, 1990). On the other hand, most items $(6.6 \%$ of $8.3 \%)$ in participation in group activities refer to activities organized by employee groups, which is quite different from the Western literature.

The fifth common dimension is promoting company image, which is similar to loyalty (Van Dyne, Graham, \& Dienesch, 1994), loyal boosterism (Moorman \& Blakely, 1995) in the Western literature. It is also similar to a dimension called identification with company, found in Taiwan by Farh, Earley, and Lin, (1997) Promoting company image includes $6.5 \%$ (38 items) of the items. 


\section{Extended Dimensions}

The first extended dimension is self-learning, which refers to improving one's knowledge or working skills through self-learning. It includes 66 items (11.2\%).

The second extended dimension is social welfare participation, which refers to employees' participation in activities of public welfare or community service nature. Sixty-one $(10.4 \%)$ of the OCB items were classified into this dimension.

The third OCB dimension in the PRC is protecting and saving company resources, which includes actions that save company resources, muster personal resources (e.g., money, information, social capital) to aid company, and protect company from disasters (e.g., fire outbreak or flood). Although this dimension was not found in the Western literature, it was one of two emic dimensions of OCB discovered in Taiwan (Farh, Earley, \& Lin, 1997). It includes $52(8.8 \%)$ of the OCB items.

The fourth extended dimension is keeping workplace clean. Forty-six (7.8\%) of the items were classified into this dimension of OCB.

The fifth extended dimension is interpersonal harmony, which refers to employee actions aimed at facilitating and preserving interpersonal harmony at workplace. This dimension was also not found in the Western literature, but was one 
of the two emic dimensions of OCB discovered in Taiwan (Farh, Earley, \& Lin, 1997). It includes 28 items (4.8\%).

The sixth (and the last) extended dimension is compliance with social norms, which refers to employee's compliance with prevailing social norms in the society (e.g., honesty, keeping promise). There are 15 items $(2.5 \%)$ that belong to this dimension of OCB.

\section{Factors That May Influence the Frequency of OCB}

\section{Respondent Position}

Table 5 reported the number as well as the percentage of items classified into each of the 11 OCB dimensions. The table also showed the percentage of items in each dimension by position of the respondent (supervisory vs. non-supervisory). These percentages inform us whether a dimension of OCB was mentioned more or less frequently or of equal frequency by respondents of different positions.

The overall frequency distribution of OCB items across supervisor versus nonsupervisor employees was compared using the Pearson Chi-square test of association. This is a test of the differences in observed and expected frequencies in each distribution using a Chi-square statistics (Hays, 1981: 544). It was found that the overall Chi-square statistics of 16.68 was nonsignificant (d.f. $=10, \mathrm{p}>.08$ ). This suggests that the distribution of OCB items across the 11 dimensions for supervisory employees is not significantly different from that for non-supervisory employees. 
Table 5 also shows the results of Chi-square tests of the percentage difference for each dimension. As shown, none of the Chi-square values is significant, consistent with the overall test. This means that respondent position bore no relation with the likelihood of OCB items represented in each OCB dimensions.

\section{Organization Type}

Table 5 also showed the percentage of items in each dimension by type of organizations in which the respondent is. The overall frequency distribution of OCB items across organization types (state-owned versus non-state owned) was also compared using the Pearson Chi-square test of association. It was found that the overall chi-square statistics of 55.52 was highly significant (d.f. $=10, p<.001)$. This suggests that the distribution of OCB items across the 11 dimensions for state-owned employees is significantly different from that for non-state owned employees.

Table 5 shows the percentage of items in each OCB dimension by respondent organization type (state-owned vs. non-state owned) and results of Chi-square tests of the percentage difference for each dimension. For common dimensions, organization type had a significant effect on taking initiative and participation in group activities only. Specifically, PRC employees from non-state owned organizations were more likely to report OCB items in taking initiative than those from state-owned organizations (20.3\% vs. 12.6\%). PRC employees from state-owned organizations were more likely to report OCB items in participation in group activities than those from non-state owned organizations (11.2\% vs. 5.5\%). 
For extended dimensions, organization type had a significant effect on selflearning, social welfare participation, protecting and saving company resources, and compliance with social norms. Specifically, PRC employees from state-owned organizations were more likely to report OCB items in self-learning (16.1\% vs. 9.2\%), social welfare participation (17.9\% vs. $5.2 \%)$, and compliance with social norms (4.9\% vs. $0.7 \%$ ) than those from non-state owned organizations. The opposite finding was found on protecting and saving company resource, where employees from nonstate owned organizations were more likely to report OCB items in that category than those from state owned organizations (12.9\% vs. $4.5 \%)$. Thus, organization type had a significant influence on the frequency of OCB items distributed across the 11 dimensions.

\section{Discussion and Conclusion}

We investigated the content domain of OCB in the PRC context. Based on over 600 behaviors listed by 166 employees from 75 different enterprises in the PRC, we identified 11 OCB dimensions. Five of the 11 dimensions are similar to the major OCB dimensions that have been investigated in the Western OCB literature. These are taking initiative, helping co-workers, voice, participation in group activities, and promoting company images. These five dimensions correspond to the Western dimensions of functional participation (also conscientiousness), altruism, voice, civic virtue, and loyalty. This suggests that these Western OCB dimensions may generalize across national boundaries. This does not mean that the specific behaviors that represent these dimensions are identical between the West and the PRC. For 
example, helping co-workers in the PRC includes non-work related helping, which is generally not considered part of altruism in the West. This inclusion of non-work related helping as part of OCB reflects the Chinese cultural tendency of mixing the private with the public spheres of life. Future researchers who wish to study these etic dimensions of OCB across cultures need to be sensitive to these differences. Applying a standard instrument across cultures without modifications may lead to deficiency and contamination in construct measurement.

\section{Extended Dimensions of OCB in the PRC}

We found that six of the 11 dimensions of OCB that seem to be unique to the PRC context. These are self-learning, social welfare participation, protecting and saving company resources, keeping workplace clean, interpersonal harmony, and compliance with social norms. However, these six may not be necessarily unique to the PRC. In particular, self-learning and keeping workplace clean are obviously not unique to the PRC. Katz and Kahn (1978), for example, argued decades ago that spending personal time on the part of an employee to master knowledge and skills for more responsible jobs in the system is a class of innovative and spontaneous behavior (self-learning). Organ (1988) suggested that the extra effort to maintain and enhance cleanliness at workplace is an often under-appreciated form of conscientiousness in many organizations. Van Dyne et al. (1994) had included an item "keeps work area clean and neat" in their measure of obedience, a major dimension of OCB according to their conceptualization. Clearly these two classes of behaviors are recognized as OCB in the PRC as well as in the West but have not received as much attention in the West. We suspect that the differential salience of these dimensions in the PRC and 
the West may be related to the different stage of economic development. Since the PRC is at an early stage of economic development, organizational support for training and development and maintenance of a clean work environment is fairly limited in most organizations in comparison with those in the West. Employee's willingness to invest in self-learning and to maintain a clean workplace are thus considered more salient forms of OCB in the PRC. Future researchers should investigate the relative importance of these two OCB dimensions across societies.

Beyond self-learning and keeping workplace clean, protecting and saving company resources is another dimension that has been mentioned, but never empirically investigated, in the West. Katz and Kahn (1978) considered actions protective of organization as one form of innovative and spontaneous behavior. George and Brief (1992) considered protecting the organizations as a key dimension of organizational spontaneity. Farh et al. (1997) found this same dimension in their study of OCB in Taiwan. These findings suggest that employee actions protective of company, resources or otherwise, is a form of OCB that has broad appeal across national boundaries. Future research should pay more attention to this aspect of OCB.

Interpersonal harmony as a form of OCB has not been proposed in the Western literature. This dimension of OCB, however, was also found in Taiwan by Farh et al. (1997). The Chinese have long been well known for their emphasis on harmony and unity (solidarity) in social relationships and within social groups. There is a good reason for Chinese to cherish interpersonal harmony because harmonious relationships foster the solidarity and integration of individual groups or organizations 
which, in turn, lead to a stable social order (Yang, 1993). Although harmony sometimes may hamper creativity or innovation, the importance of interpersonal harmony would be clear if we understood the harm of dispute in Chinese context. Trompenaars (1996) differentiated cultures in which we engage others in specific areas of life from cultures in which we engage others diffusely in multiple areas of our lives. Using a case of dispute described in the head office of a multinational company, Trompenaars demonstrated that while Americans with specific culture tried to discuss an important aspect of consistency of reward system, Italians who are from diffuse culture conceive this discussion as a personal offence and felt angry toward their American co-workers. Trompenaars measured specificity and diffuseness in different national cultures, and found that China was on the top of the diffuse culture. Based on Trompenaars's finding, we would expect that disputes in organizations in China would be more likely to develop into affect and personal conflict and cause serious problem than in the U.S. It is thus not surprising that Chinese employees in the PRC as well as in Taiwan stress the importance of interpersonal harmony and consider it to be a major form of OCB.

Among the six extended dimensions, social welfare participation is probably unique to the PRC because of its association with the legacy of communist system. Under the old central planning system, quotas of state-sanctioned activities (such as blood donating, tree planting, and adherence to one child policy) were allocated to organizations to fulfill by the central government. Meeting these quotas is important to organizations because good relationship with the government guarantees supplies of scarce resources from the government and enhancing organization's image. Organizations further allocate these quotas to divisions and eventually to employees. 
Because of organized dependency and institutional culture of authority (Walder, 1983), employees would do what organization tell them to do in order to get resources otherwise not available outside of the organization. Nowadays, although having undergone reforms for more than twenty years, employees' dependency on the organization is still high for employees in state-owned enterprises ( $\mathrm{Yu} \& \mathrm{Fu}$, In press). Such dependency no longer exists for employees in non-state organizations. It is thus not surprising that participation in social welfare activities emerged as a form of OCB for employees in state-owned enterprises but not for employees in non-state owned enterprises.

Compliance with social norms is also a dimension that seems to be unique to the PRC. According to Yang (1993), Chinese have a strong and complicated tendency to be readily influenced by other people on both psychological and behavioral levels. One of the manifestations of this tendency, called other orientation, is a deep concern about social norms. It was argued that in traditional and contemporary Chinese societies, social norms and standards are more or less important insofar as they represent other people's consensus and provide major guidelines for behavior (Yang, 1993). Anyone who violates these norms will be criticized, blamed, or punished by others. As a result, Chinese people have become highly concerned about social norms in their everyday life. Although the primary reason for people to fulfil social norms is to avoid negative and receive positive reinforcement, employees' compliance to social norms contributes to organizational effectiveness.

\section{Western OCB Dimensions Not Found in the PRC}


Three major dimensions of OCB in the Western literature were not found in the PRC context: sportsmanship, courtesy, and advocacy participation. None of these three dimensions were found in Taiwan in Farh et al. (1997). Lam et al. (1999) found that in comparison with employees from Australia and the U.S., employees from Hong Kong and Japan are more likely to consider sportsmanship and courtesy as in role behaviors. It is possible that employees from the PRC (like those from Hong Kong) also consider courtesy or sportsmanship to be in role behavior and thus did not list them. Future research should investigate why these behaviors were not considered part of OCB in a different cultural context.

Advocacy participation refers to behaviors targeted at other members of an organization and reflecting a willingness to be controversial (VanDyne et al., 1994). By definition, this category of behavior reflects the potent of being controversial, which is less palatable to Chinese who favor interpersonal harmony (Yang, 1993). Therefore, it is not surprising that advocacy participation did not emerge as a form of OCB in the PRC.

\section{Contextual Influences on OCB: Position and Organization Type}

As expected, respondent organization type had a strong influence on the reporting of $\mathrm{OCB}$ in several dimensions. In comparison with employees from nonstate owned enterprises, employees of state-owned enterprises tended to report or observe more participation in group activities, self-learning, social welfare participation, and compliance with social norms. State employees also tended to report or observe fewer OCBs involving taking initiative and protecting and saving 
company resources than employees of non-state owned enterprises. These findings are generally consistent with our expectation that employees of state-owned enterprises tend to be influenced by legacy of pre-reform policies of the communist government. Somewhat unexpected is the lack of influence of respondent position on the reporting of OCB. This suggests that position is not as important as organization type in affecting the reporting of OCB in the PRC. To what extent that these findings can generalize to the Western culture needs to be addressed in future research.

\section{Concentric Model of OCB}

In this study we have identified 11 dimensions of OCB in the PRC. We propose a preliminary concentric model to classify these dimensions into four major domains. Before we describe our model, let us examine the current classification scheme in the literature.

Smith, Organ and Near (1983) identified two dimensions of OCB: altruism and generalized compliance. The former refers to behaviors that are directly and intentionally aimed at helping a specific person. The latter, however, is more impersonal and aims at benefiting the organization in general. Based on the target or beneficiary of the action, Williams and Anderson (1991) suggested that we label the former as OCB-interpersonal (OCBI) and the latter as OCB-organizational (OCBO). Similarly, Barr and Pawar (1995) suggested that we should further split OCBI into two subcategories: a) co-worker domain and b) supervisor domain. Both schemes classify OCB based on the target or the beneficiary of the action. Both schemes could not be adequately applied to the 11 dimensions of OCB we found in the PRC. For 
example, how would one classify social welfare participation or self-learning? We need a scheme that goes beyond the target or beneficiary of action.

In our model, we proposed to classify OCB based on foci of action, not on the intended target or beneficiary of action. According to foci of action, all OCB can be classified into four domains, which begins with self to group to organization and then finally to outsiders and society. The circle moves from self and then spread out to increasingly larger groups (see Figure 1). The self domain includes three types of OCB: self-learning, taking initiative, and keeping workplace clean. All of these activities are self focused since they rely on individuals' self-discipline or selfinitiation to carry out. The group domain includes two dimensions: interpersonal harmony and helping co-workers. Both of the expressions of interpersonal harmony and helping co-workers rely on the underlying interpersonal interaction. The organization dimension includes protecting and saving company resources, and voice. These activities do not relate to specific people yet contribute to organizational effectiveness in general. The society dimension includes social welfare participation, compliance with social norms, and protecting company image to others outside the company.

Our model is not a simple extension of models identified by Western scholars that emphasize the beneficiary of OCB. We adopted a different criterion of classification that stress the context where OCB occurs, or the expression of OCB. A problem with using beneficiary of OCB as a criterion for classification is that most forms of OCB are classified as OCBO, or OCB directed at organization. Out of the nine dimensions listed in Table 1, only two (altruism and advocacy participation) 
could be classified as OCBI. The preliminary concentric model overcomes this problem.

\section{Conclusion}

The structure of the OCB identified in the PRC should be examined in other contexts using a similar method. Only after we have conducted the same approach in the U.S. and identified similar structure of etic and emic dimensions of OCB, we could have more confidence in claiming that our structure of etic and emic dimensions of OCB is valid.

Although we argued that the form of OCB in the PRC is embedded in its social and cultural context, our conceptualizations of characteristics of the social and culture context in the PRC (such as social orientation) are not unique to the PRC. We should be able to directly measure these contextual variables and relate them to the OCB conceptualization in different contexts. By doing so, we would be immune to the common criticism on cross-cultural research that specific cultural variables should be measured and validated rather than merely assumed and then using country as an indicator. 


\section{Reference}

Anderson, J. C., \& Gerbing, D. W. 1991. Predicting the performance of measures in a confirmatory factor analysis with a pretest assessment of their substantive validities. Journal of Applied Psychology, 76: 732-741.

Barr, S. H., \& Pawar, B. S. 1995. Organizational Citizenship Behavior: Domain specifications for three middle range of theories. Academy of Management Journal, Best papers proceedings: 302-306.

Borman, W. C., \& Motowidlo, S. J. 1993. Expanding the criterion domain to include elements of contextual performance. In N. Schmitt \& W. Borman (Eds.), Personnel selection in organizations: 71-98. New York: Jossey-Bass.

Brief, A. P., \& Motowidlo, S. J. 1986. Prosocial Organizational Behaviors. Academy of Management Review, 11: 710-725.

Farh, J. L., Earley, P. C., Lin, S., \&. 1997. Impetus for action: A cultural analysis of justice and extra-role behavior in Chinese society. Administrative Science Quarterly, 42: 421-444.

Farh, J. L., Tsui, A. S., Xin, K. R., \& Cheng, B. S. 1997. The influence of relational demography and guanxi: The Chinese case. Organization Science, 9: 471-488.

George, J. M., \& Brief, A. P. 1992. Feeling good-doing good: A conceptual analysis of the mood at work-organizational spontaneity relationship. Psychological Bulletin, 112: 310-329.

Graen, G. 1976. Role making processes within complex organizations. In M. D. Dunnette (Ed.), Handbook of industrial and organizational psychology: 1201-1245. Chicago: Rand McNally.

Graham, J. W. 1991. An essay on organizational citizenship behaivor. Employee Responsibilities and Rights Journal, 4: 249-270.

Hays, W. L. 1981. Statistic. $3^{\text {rd }}$ Edition. New York: Holt, Rinehart and Winston.

Hinkin, T. R. 1998. A brief tutorial on the development of measures for use in survey questionnaires. Organizational Research Methods, 1: 104-121.

Hsu, F. L. K. 1971. Psychological homeostasis and jen: conceptual tools for advancing psychological anthropology. American Anthropologist, 73: 23-44.

Katz, D. 1964. The motivational basis of organiztioal behavior. Behavioral Science, 9: 131-146.

Katz, D., \& Kahn, R. L. 1978. The social psychology of organizations. New York: Wiley. 
Kerlinger, F. N. 1986 Foundations of behavioral research. Fort Worth: Holt, Rinehart and Winston.

Lam, S. S. K., Hui, C., \& Law, K. S. 1999. Organizational citizenship behavior: comparing perspectives of supervisors and subordinates across four international samples. Journal of Applied Psychology, 84: 594-601

Moorman, R. H., \& Blakely, G. L. 1995. Individualism-collectivism as an individual difference predictor of organizational citizenship behavior. Journal of Organizational Behavior, 16: 127-143.

Morrison, E. W. 1994. Role definitions and organizational citizenship behavior: The importance of the employee's perspective. Academy of Management Journal, 37: 1543-1567.

Motowidlo, S. J., Borman, W. C., \& Schmit, M. J. 1997. A theory of individual difference in task and contextual performance. Human Performance, 10: 71-83.

Nyaw, M. K. 1995. Human Resource Management in the People's Republic of China. In L. F. Moore, \& P. D. Jennings (Eds.), Human Resource Management on the Pacific Rim: 187-216. New York: Walter de Gruyter.

Organ, D. W. 1988. Organizational Citizenship Behavior: The good soldier syndrome. Lexington, MA: Lexington Books.

Organ, D. W. 1997. Organizational Citizenship Behavior: It's construct clean-up time. Human Performance, 10: 85-97.

Podsakoff, P. M., MacKenzie, S. B., Moorman, R. H., \& Fetter, R. 1990. Transformational leader behaviors and their effects on followers' trust in leader, satisfaction, and Organizational Citizenship Behaviors. Leadership Quarterly, 1: 107142.

Salancik, G. R. \& Pfeffer, J. 1978. A social information processing approach to job attitudes and task design. Administrative Science Quarterly, 23: 224-253.

Smith, C. A., Organ, D.W., \& Near, J. P. 1983. Organizational Citizenship Behavior: Its Nature and Antecedents. Journal of Applied Psychology, 68: 653-663.

Trompenaars, F. 1996. Riding the waves of culture. London: Nicholas Brealey.

Tsui, A. S., \& Farh, J. L. 1997. Where gunaxi matters: Relational demography and gunaxi in the Chinese context. Work and Occupations, 24: 56-79.

Van de Vijver, F., \& Leung, K. 1997. Methods and data analysis for cross-cultural research. London: SAGE. 
Van Dyne, L., Cummings, L. L., \& McLean Parks, J. M. 1995. Extra-Role Behaviors: In pursuit of construct and definitional clarity (A bridge over muddied waters). Research in Organizational Behavior, 17: 215-285.

Van Dyne, L., Graham, J. W., \& Dienesch, R. M. 1994. Organizational Citizenship Behavior: Construct redefinition, measurement, and validation. Academy of Management Journal, 37: 765-802.

Van Dyne, L., \& LePine, J. A. 1998. Helping and voice extra-role behaviors: Evidence of construct and predictive validity. Academy of Management Journal, 41: 108-119.

Van Scotter, J. R., \& Motowidlo, S. J. 1996. Interpersonal facilitation and job dedication as separate facets of contextual performance. Journal of Applied Psychology, 81: 525-531.

Walder, A. G. 1983. Organized dependency and cultures of authority in Chinese industry. Journal of Asian Studies, XLIII: 51-76.

Williams, L. J., \& Anderson, S. E. 1991. Job satisfaction and organizational commitment as predictors of organizational citizenship and in-role behavior. Journal of Management, 17: 601-617.

Xin, K. R., \& Pearce, J. L. 1996 Guanxi: Connections as substitutes for formal institutional support. Academy of Management Journal, 39: 1641-1658.

Yang, K. S. 1993. Chinese Social Orientation: An integrative analysis. In Louis, Y. C. Cheng, Fanny, M. C. Cheung, \& C. N. Chen (Eds.), Psychotherapy for the Chinese-selected papers from the First International Conference, 9-11 November, 1992: 19-55. 


\section{Table 1}

OCB Dimensions identified in the Western literature

\begin{tabular}{ll}
\hline Dimension & Definition \\
\hline Altruism & $\begin{array}{l}\text { Discretionary behavior that have the effect of } \\
\text { helping a specific other person with an } \\
\text { organizationally relevant task or problem }\end{array}$
\end{tabular}

Source

Smith, Organ \& Near, 1983; Organ,

1988; Podsakoff, et al., 1990.

Similar dimension also include Helping

(VanDyne, et al., 1998) and Interpersonal

helping (Graham, 1989; Moorman, et al.,

1995)

Conscientiousness Discretionary behaviors on the part of an

Smith, et al., 1983; Organ, 1988;

employee that go well beyond the minimum

Podsakoff, et al., 1990.

role requirements of the organization, in the

Similar dimension also include

areas of attendance, obeying rules and

Obedience (Graham, 1989; VanDyne, et

regulations, taking breaks, and so forth

al., 1994), and Personal industry

(Graham, 1989; Moorman, et al., 1995)

\begin{tabular}{ll}
\hline Sportsmanship & $\begin{array}{l}\text { Willingness of an employee to tolerate less } \\
\text { than ideal circumstances without } \\
\text { complaining-to "avoid complaining, petty } \\
\text { grievances, railing against real or imagined } \\
\text { slights, and making federal cases out of small } \\
\text { potatoes" }\end{array}$ \\
\hline Courtesy & $\begin{array}{l}\text { Discretionary behavior on the part of an } \\
\text { individual aimed at preventing work-related } \\
\text { problem with others from occurring }\end{array}$
\end{tabular}

Organ, 1988; Podsakoff, et al., 1990.

Organ, 1988; Podsakoff, et al., 1990.

Civic virtue

Functional

participation
Behavior on the part of the individual that indicates that he/she responsible participates in, is involved in, or is concerned about the life of the organization

Participation contribution in which individuals focus on themselves rather than others in their organizations but yet contribute to organizational effectiveness Behaviors targeted at others of an
organization and reflecting a willingness to be
controversial. Such as encouraging quiet person to speak up in meetings and helps coworkers think for themselves
Graham, 1986; Organ, 1988; Podsakoff, et al., 1990.

VanDyne, et al., 1994.

VanDyne, et al., 1994.

Similar dimension include Individual initiative (Graham, 1989; Moorman, et al., 1995).

\begin{abstract}
Loyalty Allegiance to an organization and promotion of its interests.
\end{abstract}

Promotive behavior that emphasizes expression of constructive challenge intended to improve rather than merely criticize.
Graham, 1989; VanDyne, et al., 1994. Similar dimension also include Loyal boosterism (Graham, 1989; Moorman, et al., 1995).

VanDyne, \& Parks, 1995; VanDyne \& LePine, 1998) 
TABLE 2

Sample Characteristics ( $\mathrm{N}=166)$

\begin{tabular}{|c|c|c|}
\hline Characteristics & Frequency * & Percentage \\
\hline \multicolumn{3}{|l|}{ Locality } \\
\hline Beijing & 35 & 21.1 \\
\hline Shanghai & 99 & 59.6 \\
\hline Hangzhou & 8 & 4.8 \\
\hline Shengzhen & 24 & 14.5 \\
\hline \multicolumn{3}{|l|}{ Types of enterprise } \\
\hline State owned & 60 & 37.0 \\
\hline Collective & 10 & 6.2 \\
\hline Foreign investment & 51 & 31.5 \\
\hline Private & 16 & 9.9 \\
\hline Others & 25 & 15.4 \\
\hline \multicolumn{3}{|l|}{ Organization Size } \\
\hline Less than 88 & 40 & 25.2 \\
\hline $88-200$ & 41 & 25.8 \\
\hline $200-700$ & 39 & 24.5 \\
\hline More than 700 & 39 & 24.5 \\
\hline \multicolumn{3}{|l|}{ Positions } \\
\hline Supervisory & 92 & 57.1 \\
\hline Nonsupervisory & 69 & 42.9 \\
\hline \multicolumn{3}{|l|}{ Age } \\
\hline $21-30$ & 62 & 38.3 \\
\hline $31-40$ & 61 & 37.7 \\
\hline $41-50$ & 39 & 24.1 \\
\hline \multicolumn{3}{|l|}{ Gender } \\
\hline Male & 97 & 59.5 \\
\hline Female & 66 & 40.5 \\
\hline \multicolumn{3}{|l|}{ Education } \\
\hline High school & 45 & 27.6 \\
\hline Vocational school & 47 & 28.8 \\
\hline Undergraduate & 71 & 43.6 \\
\hline
\end{tabular}

* Frequencies may not add up to 166 for some characteristics due to missing data. 


\section{TABLE 3}

Item characteristics

\begin{tabular}{lrc}
\hline Types & Items & Percentages \\
Total number of items & 756 & 100 \\
Usable items & 690 & 91.3 \\
Non-usable items & 66 & 8.7 \\
\hline Results of reliability test & & \\
Full (three) agreements * & 509 & 73.8 \\
Two agreements & 100 & 14.5 \\
One agreement & 62 & 9.0 \\
$\quad$ No agreement & 19 & 2.8 \\
& & \\
\hline Final item distribution (out of total number of items) & & \\
Total & 756 & 100 \\
Non-usable items & 66 & 8.7 \\
Ambiguous items & 75 & 10.0 \\
Clear items & 615 & 81.3 \\
\hline
\end{tabular}

* This refers to the extent to which the test judges agree with the researchers on the designation of an OCB item into 27 a priori categories. 
Table 4

OCB Dimensions in the PRC

\begin{tabular}{|c|c|c|}
\hline \multicolumn{3}{|l|}{ Common dimension } \\
\hline Definition & Sample items & Corresponding Western OCB dimension \\
\hline $\begin{array}{l}\text { Taking initiative (103 items) } \\
\text { Takes initiative in working overtime, taking on } \\
\text { extra responsibilities and being cooperative at } \\
\text { work }\end{array}$ & $\begin{array}{l}\text { - Volunteer for overtime work when needed } \\
\text { - Willingness to take extra responsibilities. (e.g., } \\
\text { help solve customers' problems) } \\
\text { - Share creative ideas with colleagues }\end{array}$ & $\begin{array}{l}\text { Functional participation (Van Dyne, Graham, \& } \\
\text { Dienesch, 1994) } \\
\text { Job dedication (Van Scotter \& Motowidlo, 1996) }\end{array}$ \\
\hline $\begin{array}{l}\text { Helping coworkers ( } \mathbf{7 2} \text { items) } \\
\text { Helps coworkers with job-related or personal } \\
\text { matters }\end{array}$ & $\begin{array}{l}\text { - Help others with urgent and heavy work loads } \\
\text { - Loan money to co-workers who have financial } \\
\text { difficulties }\end{array}$ & $\begin{array}{l}\text { Altruism (Smith, Organ \& Near, 1983; Organ, } \\
\text { 1988; Posdakoff, MacKenzie, Moorman \& Fetter, } \\
\text { 1990) } \\
\text { Helping (Van Dyne \& LePine, 1998) }\end{array}$ \\
\hline $\begin{array}{l}\text { Voice (57 items) } \\
\text { Expression of constructive/prohibitive } \\
\text { challenges on behalf of organization. }\end{array}$ & $\begin{array}{l}\text { - } \text { Make recommendations to improve procedures } \\
\text { - Remind co-workers not to do actions harmful to } \\
\text { organization }\end{array}$ & Voice (Van Dyne \& LePine, 1998) \\
\hline $\begin{array}{l}\text { Participation in group activities ( } 49 \text { items) } \\
\text { Discretionary participation on the part of the } \\
\text { individual in activities organized by group of } \\
\text { employees or organization }\end{array}$ & $\begin{array}{l}\text { - Attend meetings that are not required } \\
\text { - Participates in activities organized by employees } \\
\text { such as family party and sports game }\end{array}$ & $\begin{array}{l}\text { Civic virtue (Organ, 1988; Posdakoff, MacKenzie, } \\
\text { Moorman \& Fetter, 1990) }\end{array}$ \\
\hline $\begin{array}{l}\text { Promoting company image ( } 38 \text { items) } \\
\text { The promotion of the organizational image to } \\
\text { outsiders }\end{array}$ & $\begin{array}{l}\text { - Represent organization favorably to outsiders } \\
\text { - Introduce and expand business of organization to } \\
\text { acquaintance and relatives using personal time }\end{array}$ & $\begin{array}{l}\text { Loyalty (Van Dyne, Graham, \& Dienesch, 1994) } \\
\text { Loyal boosterism (Moorman \& Blakely’s, 1995) }\end{array}$ \\
\hline
\end{tabular}


Table 4, continued

OCB Dimensions in the PRC

\begin{tabular}{|c|c|}
\hline Extended dimension & \\
\hline Definition & Sample items \\
\hline $\begin{array}{l}\text { Self learning (66 items) } \\
\text { Improve knowledge or working skills through self-learning. }\end{array}$ & $\begin{array}{l}\text { - Spend spare time in learning and improving skills } \\
\text { - } \quad \text { Acquire work-related knowledge at one's own costs }\end{array}$ \\
\hline $\begin{array}{l}\text { Social welfare participation ( } 61 \text { items) } \\
\text { Perform services that contribute to social welfare }\end{array}$ & $\begin{array}{l}\text { - Participate in social welfare activities, such as donating money and planting } \\
\text { trees } \\
\text { - Participation in community service, such as aiding elders in the community }\end{array}$ \\
\hline $\begin{array}{l}\text { Protecting and saving company resource ( } 52 \text { items) } \\
\text { Save company resources by either protecting company resources or } \\
\text { making personal resources available for company use }\end{array}$ & $\begin{array}{l}\text { - Save company resources such as electricity and water } \\
\text { - Provide organization with free personal resources such as information and social } \\
\text { network } \\
\text { - Protect factories against flood }\end{array}$ \\
\hline $\begin{array}{l}\text { Keeping workplace clean ( } 46 \text { items) } \\
\text { Keep workplace clean and neat }\end{array}$ & $\begin{array}{l}\text { - Clean up workplace using personal time } \\
\text { - Keep one's workplace and archives in order }\end{array}$ \\
\hline $\begin{array}{l}\text { Interpersonal Harmony (28 items) } \\
\text { Maintain and establish interpersonal harmony at work place. }\end{array}$ & $\begin{array}{l}\text { - Maintain good relationships with co-workers } \\
\text { - Help resolve conflict and misunderstanding among co-workers }\end{array}$ \\
\hline $\begin{array}{l}\text { Compliance with social norms ( } 15 \text { items) } \\
\text { Follow social norms and regulations. }\end{array}$ & $\begin{array}{l}\text { - } \text { Be honest and credible in personal conduct } \\
\text { - Compliance with social norms (e.g., do not spit) }\end{array}$ \\
\hline
\end{tabular}




\section{Table 5}

\section{OCB Item Distribution by Respondent Position and Organization Type}

\section{OCB dimension}

\begin{tabular}{|c|c|c|c|c|c|c|c|}
\hline \multirow[b]{2}{*}{ 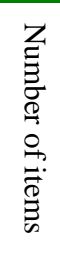 } & \multirow[b]{2}{*}{ 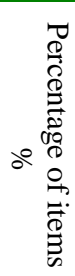 } & \multicolumn{3}{|c|}{ Position } & \multicolumn{3}{|c|}{ Organizational type $c$} \\
\hline & & 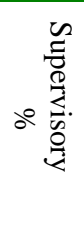 & 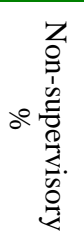 & $\begin{array}{l}\text { Chi-Square } \\
\text { test }\end{array}$ & 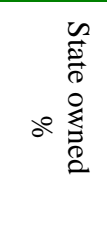 & 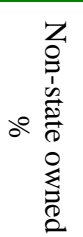 & $\begin{array}{l}\text { Chi- } \\
\text { Square } \\
\text { test }\end{array}$ \\
\hline
\end{tabular}

\section{Common dimension}

\begin{tabular}{lrrrrrrrr}
\hline 1. Taking initiative & $\mathbf{1 0 3}$ & $\mathbf{1 7 . 5}$ & $\mathbf{1 8 . 6}$ & $\mathbf{1 6 . 5}$ & $\mathbf{0 . 4 5}$ & $\mathbf{1 2 . 6}$ & $\mathbf{2 0 . 3}$ & $\mathbf{5 . 4 1 *}$ \\
Cooperation at work & 5 & 0.8 & 0.3 & 1.5 & & 0.9 & 0.7 & \\
Work overtime & 53 & 9.0 & 8.8 & 9.4 & & 5.8 & 9.2 & \\
Activism at work & 33 & 5.6 & 7.2 & 3.7 & & 4.0 & 7.7 & \\
Information sharing & 12 & 2.0 & 2.3 & 1.9 & & 1.8 & 2.6 & \\
\hline 2. Helping coworkers & $\mathbf{7 2}$ & $\mathbf{1 2 . 2}$ & $\mathbf{1 4 . 7}$ & $\mathbf{9 . 7}$ & $\mathbf{3 . 2 4}$ & $\mathbf{8 . 5}$ & $\mathbf{1 4 . 0}$ & $\mathbf{3 . 7 4}$ \\
Work-related helping & 31 & 5.3 & 5.9 & 4.9 & & 2.7 & 7.7 & \\
Non-work helping & 41 & 7.0 & 8.8 & 4.9 & & 5.8 & 6.3 & \\
\hline 3. Voice & $\mathbf{5 7}$ & $\mathbf{9 . 7}$ & $\mathbf{1 1 . 4}$ & $\mathbf{7 . 1}$ & $\mathbf{3 . 1 1}$ & $\mathbf{8 . 1}$ & $\mathbf{1 0 . 7}$ & $\mathbf{1 . 0 4}$ \\
Constructive suggestion & 39 & 6.6 & 8.5 & 4.5 & & 6.3 & 7.0 & \\
Prohibitive voice & 18 & 3.1 & 2.9 & 2.6 & & 1.8 & 3.7 & \\
\hline 4. Participation in group activities & $\mathbf{4 9}$ & $\mathbf{8 . 3}$ & $\mathbf{7 . 2}$ & $\mathbf{1 0 . 1}$ & $\mathbf{1 . 5 6}$ & $\mathbf{1 1 . 2}$ & $\mathbf{5 . 5}$ & $\mathbf{5 . 1 8}$ \\
Group activities participation & 39 & 6.6 & 6.2 & 7.5 & & 10.8 & 3.7 & \\
Organizational activities participation & 10 & 1.7 & 1.0 & 2.6 & & 0.4 & 1.8 & \\
\hline 5. Promoting company image & $\mathbf{3 8}$ & $\mathbf{6 . 5}$ & $\mathbf{5 . 6}$ & $\mathbf{7 . 5}$ & $\mathbf{0 . 8 9}$ & $\mathbf{5 . 8}$ & $\mathbf{6 . 6}$ & $\mathbf{0 . 1 5}$
\end{tabular}

\section{Extended dimension}

\begin{tabular}{lrrrrrrrr}
\hline 6. Learning Self & $\mathbf{6 6}$ & $\mathbf{1 1 . 2}$ & $\mathbf{1 1 . 8}$ & $\mathbf{1 0 . 9}$ & $\mathbf{0 . 1 1}$ & $\mathbf{1 6 . 1}$ & \multicolumn{1}{c}{$\mathbf{9 . 2}$} & \multicolumn{1}{c}{$\mathbf{5 . 2 7} *$} \\
\hline 7. Social welfare participation & $\mathbf{6 1}$ & $\mathbf{1 0 . 4}$ & $\mathbf{7 . 5}$ & $\mathbf{1 2 . 4}$ & $\mathbf{3 . 8 0}$ & $\mathbf{1 7 . 9}$ & $\mathbf{5 . 2}$ & $\mathbf{2 0 . 2 3 * *}$ \\
Contribution to public welfare & 47 & 8.0 & 5.9 & 9.4 & & 12.6 & 4.4 & \\
Serve the interests of community & 14 & 2.4 & 1.6 & 3.0 & & 5.4 & 0.7 & \\
\hline 8. Protecting and saving company resources & $\mathbf{5 2}$ & $\mathbf{8 . 8}$ & $\mathbf{7 . 8}$ & $\mathbf{1 0 . 1}$ & $\mathbf{0 . 9 1}$ & $\mathbf{4 . 5}$ & $\mathbf{1 2 . 9}$ & $\mathbf{1 0 . 6 7 * *}$ \\
Save resources & 33 & 5.6 & 4.2 & 7.1 & & 3.1 & 7.4 & \\
Personal resources for company use & 11 & 1.9 & 1.0 & 3.0 & & 1.3 & 2.6 & \\
Protect company against disasters & 8 & 1.4 & 2.6 & 0 & & 0 & 3.0 & \\
\hline 9. Keeping workplace clean & $\mathbf{4 6}$ & $\mathbf{7 . 8}$ & $\mathbf{8 . 8}$ & $\mathbf{7 . 1}$ & $\mathbf{0 . 5 6}$ & $\mathbf{6 . 3}$ & $\mathbf{8 . 9}$ & $\mathbf{1 . 1 9}$ \\
\hline 10. Interpersonal harmony & $\mathbf{2 8}$ & $\mathbf{4 . 8}$ & $\mathbf{4 . 9}$ & $\mathbf{4 . 5}$ & $\mathbf{0 . 0 5}$ & $\mathbf{4 . 0}$ & $\mathbf{5 . 2}$ & $\mathbf{0 . 3 7}$ \\
\hline 11. Compliance with social norms & $\mathbf{1 5}$ & $\mathbf{2 . 5}$ & $\mathbf{1 . 3}$ & $\mathbf{3 . 7}$ & $\mathbf{3 . 5 6}$ & $\mathbf{4 . 9}$ & $\mathbf{0 . 7}$ & $\mathbf{8 . 3 2} * *$ \\
\hline \multicolumn{1}{c}{ Total } & $\mathbf{5 8 7}$ & $\mathbf{1 0 0}$ & $\mathbf{1 0 0}$ & $\mathbf{1 0 0}$ & & $\mathbf{1 0 0}$ & $\mathbf{1 0 0}$ & \\
\hline
\end{tabular}

a. With the exception of column 2 where number of items are reported for each dimension, the rest of the entries in the table were percentage. For example, the first entry in column 3 (i.e. 16.5) indicates that $16.5 \%$ of the OCB items listed by non-supervisory personnel were classified as "initiative" items.

b. The number of items listed by non-supervisory employee was 266 , by supervisory employee 305 ; by employees of state-owned enterprises 223, by non-state-owned enterprises 269; by employees of high school education 164, by employees of vocational school education 162, by employees of university education 253 .

c. Non-state-owned companies include collective, joint venture, and private companies. 


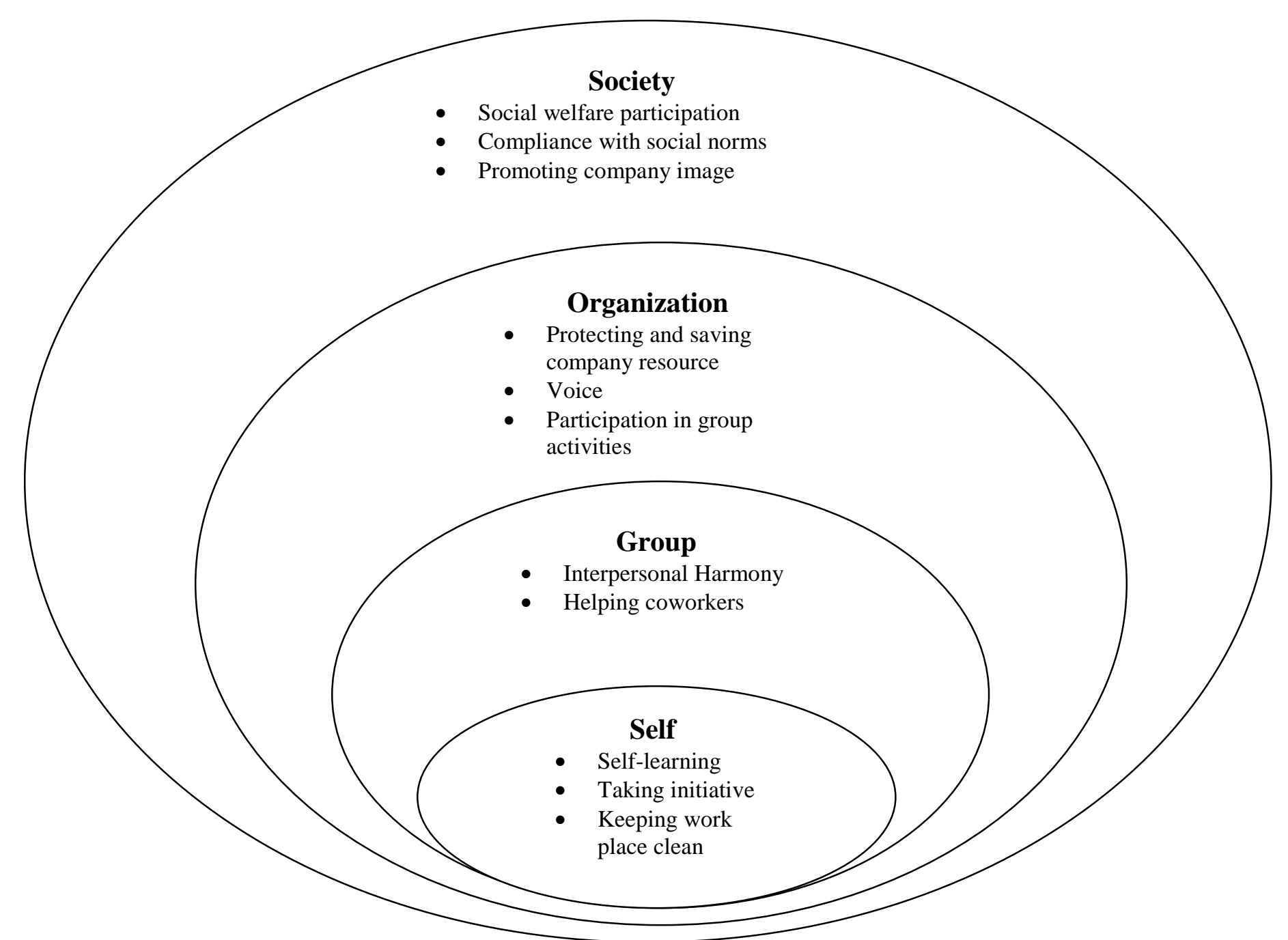

Figure 1. A Concentric Model of OCB Dimension 